\title{
Análise e Ranqueamento da Rede de Advogados induzida por Processos Judiciais Trabalhistas
}

\author{
Leonardo Filipe Rodrigues Ribeiro ${ }^{1}$, Daniel R. Figueiredo ${ }^{1}$, \\ Paulo Roberto Nascimento ${ }^{1}$
}

\author{
${ }^{1}$ Programa de Engenharia de Sistemas e Computação (PESC/COPPE) \\ Universidade Federal do Rio de Janeiro (UFRJ) - Rio de Janeiro - RJ \\ leoribeiro@cos.ufrj.br, danieldland.ufrj.br, prmn@cos.ufrj.br
}

\begin{abstract}
Who are the most important lawyers in the labor court of Rio de Janeiro state? Using data from tens of thousands of cases, we created a network of lawyers, directed and weighted, in order to answer that and some other questions. An empirical evaluation indicates that the structure of the network has very commonly features founded in other real social networks. Metrics as closeness, betweenness, vertex strength and pagerank were used to perform ranking of its vertices and identifying the main lawyers of the network. Lastly, we found information about how lawyers are related to each other in the different trials in which they worked. The main objective of this work is to understand how labor lawyers are connected and what their importance is in the community in which they work.
\end{abstract}

Resumo. Quais são os advogados mais influentes da justiça do trabalho do estado do Rio de Janeiro? Utilizando dados de dezenas de milhares de processos, construímos uma rede de advogados, direcionada e com pesos, com o objetivo de responder a essa e algumas outras perguntas. Uma avaliação empírica indica que a estrutura da mesma apresenta características muito comumente encontradas em outras redes sociais reais. As métricas closeness, betweenness, força do vértice e pagerank foram utilizadas para realizar o ranqueamento dos seus vértices e identificar os principais advogados da rede. Por fim, identificamos como os advogados estão relacionados nos diferentes processos onde atuaram. O principal objetivo desse trabalho é entender como os advogados trabalhistas estão conectados e qual sua importância na comunidade em que trabalham.

\section{Introdução}

A solução judicial de conflitos decorrentes das relações de trabalho, segundo a Constituição, é de competência da Justiça do Trabalho, a qual está estruturada em um Tribunal Superior do Trabalho (TST), com competência em todo o território nacional, e 24 Tribunais Regionais do Trabalho (TRT) distribuídos pelo país. O Tribunal Regional do Trabalho - $1^{\text {a }}$ Região (TRT1) tem competência para julgar os processos trabalhistas no âmbito do Estado do Rio de Janeiro.

Os processos de natureza trabalhista são norteados pelos princípios e normas do Direito Processual do Trabalho. Um processo possui um autor, também chamado de reclamante na reclamação trabalhista, e um réu, também chamado de reclamado. Na 
justiça do trabalho reclamante é aquele que aciona o judiciário, geralmente o empregado, ao passo que reclamado é aquele que é chamado a se defender perante o juízo, em geral é a empresa ou empregador.

Atualmente, todos os novos processos iniciados no TRT1 são eletrônicos. Para isso, utiliza-se o Processo Judicial Eletrônico da Justiça do Trabalho (PJe-JT), que é um sistema desenvolvido pelo Conselho Superior da Justiça do Trabalho (CSJT) a partir de um branch do Processo Judicial Eletrônico (PJe), o qual é desenvolvido pelo Conselho Nacional de Justiça (CNJ) em parceria com tribunais e tendo a participação da Ordem dos Advogados do Brasil. O PJe-JT foi implantado no TRT1 em junho de 2012 e hoje já conta com mais de 713 mil processos na $1^{\text {a }}$ instância e mais de 57 mil processos na $2^{\mathrm{a}}$ instância. Todos os atos e documentos de processos PJe-JT são eletronicamente cadastrados. Os dados são públicos, salvo aqueles em segredo de justiça, e podem ser acessados através do portal do tribunal.

Este trabalho utiliza as informações dos processos judiciais trabalhistas oriundas da base de dados do sistema PJe-JT, em particular, informações das partes reclamante e reclamada. Essas partes possuem um ou mais advogados. Apesar do portal público, estas informações foram obtidas diretamente do banco de dados do PJe-JT e os dados foram anonimizados, de forma que os nomes dos advogados foram transformados em números aleatórios a fim de preservar a privacidade dos advogados.

Iremos construir uma rede de advogados onde os vértices representam os advogados e uma aresta direcionada de um advogado $A$ para um advogado $B$ indica que $A$ "perdeu" um ou mais processos para $B$. As arestas possuem pesos, então se o advogado $A$ perdeu $k$ processos para o advogado $B$, existirá uma aresta direcionada de $A$ para $B$ com peso $k$. A ideia é que um advogado, ao perder um processo para outro, está conferindo importância ao segundo. Logo, um advogado que possui muitas arestas de entrada e poucas de saída terá um maior prestígio na rede de advogados, por ter vencido muitos processos e perdido poucos.

A Figura 1 mostra um pequeno pedaço da rede de advogados, mais especificamente advogados que atuaram na $2^{\text {a }}$ Vara de Macaé. Os advogados 38846 e 681953 ganharam dois e cinco processos, respectivamente, do advogado 492270. Os advogados 111275 e 44401 perderam e ganharam entre si um processo, e o mesmo ocorreu entre os advogados $\mathbf{4 4 4 0 1}$ e $\mathbf{4 9 2 2 7 0}$. Repare as intensidades (pesos) das arestas, e a possibilidade de reciprocidade entre um par de advogados ( $A$ perde para $B$, e vice-versa).

As principais contribuições deste trabalho são a construção, caracterização e ranqueamento de uma rede empírica de advogados a partir de processos judiciais. A caracterização desta rede indica que a mesma possui propriedades tipicamente encontradas em redes sociais, tais como baixa densidade, distâncias curtas e distribuição de grau com cauda pesada. A partir da rede, realizamos um ranqueamento utilizando métricas distintas (pagerank e força do vértice, entre outras) com o objetivo de identificar os advogados mais influentes. Ao final, comparamos o ranqueamento com o valor monetário dos processos envolvendo os respectivos advogados, que indica uma correlação com o ranqueamento.

O restante desse artigo está organizado da seguinte forma: na seção 2 apresentamos os trabalhos relacionados; uma descrição dos detalhes do dataset e de como foi 


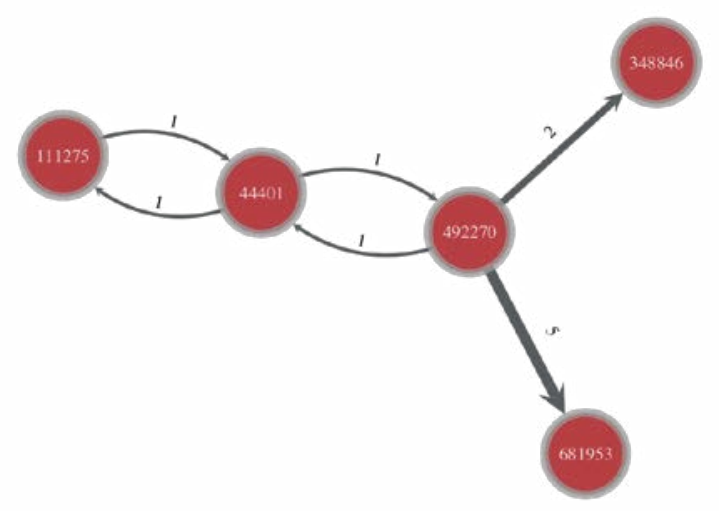

Figura 1. Rede de advogados com pesos nas arestas que indicam vitórias em processos julgados.

criada a rede são exibidos na seção 3; na seção 4 é apresentada a análise da rede; o ranqueamento dos advogados é relatado na seção 5 e as conclusões são traçadas na seção 6.

\section{Trabalhos Relacionados}

Em [16] é feita uma análise estrutural de uma rede de tenistas criada com base nos dados da Associação de Tenistas Profissionais (ATP). É proposto um ranking de tenistas utilizando um algoritmo análogo ao pagerank. Em [8] são produzidos ranqueamentos em redes sociais esportivas, levando em conta o aspecto temporal inerentemente presente nos esportes para realizar o cálculo dos pesos das arestas da rede, capturando a noção de que resultados mais antigos não são tão importantes quanto resultados mais recentes, para a criação de um ranqueamento atual.

Em [6] foi criada a "Rede da Lei", uma rede com várias citações feitas em casos, estatutos ou por autoridades na área da jurídica nos EUA. O objetivo é caracterizar e entender como o sistema legal americano tem se comportado. Essa rede possui várias semelhanças estruturais com a Web.

Newman [12][13] caracteriza redes de colaborações científicas onde os vértices são cientistas e haverá uma aresta entre dois cientistas se eles foram co-autores em um ou mais artigos científicos. O estudo mostra diversas propriedades da rede criada como curtas distâncias entre cientistas, a presença de agrupamentos, além de diferentes padrões encontrados dependendo do campo de colaboração estudado.

Em [7] é explorado como padrões presentes na rede de interações entre pessoas de uma organização afetarem a percepção que os empregados têm uns dos outros. Isso acontece através da influência social baseada na proximidade das pessoas e do poder exercido baseado na centralidade da rede. Os resultados sugerem que algumas características da rede explicam melhor as percepções que as pessoas têm umas das outras, do que atributos individuais ou posições formais na organização.

\section{Dataset e Rede}

Os dados dos processos utilizados na criação da rede de advogados trabalhistas do estado do Rio de Janeiro foram capturados do sistema PJe-JT. Selecionamos processos 
eletrônicos distribuídos de junho de 2012 à outubro de 2015 e dentre estes selecionamos somente processos pertencentes às seguintes classes processuais: Ação Trabalhista - Rito Sumário (Alçada), Ação Trabalhista - Rito Sumaríssimo e Ação Trabalhista - Rito Ordinário.

O Rito Sumário, também chamado de alçada, é regulado pela lei 5584/70, e abrange as causas de pequeno valor que não excedam a dois salários mínimos. Ele foi criado no intuito de acelerar a resolução dos processos individuais do trabalho, não permitindo recursos e limitado a três testemunhas por parte. Devido ao valor muito baixo dos processos que se sujeitam ao Rito Sumário, o mesmo se revelou pouco eficiente nas regiões sul e sudeste do Brasil, regiões em que as demandas processuais trabalhistas superam em sua esmagadora maioria o valor de dois salários mínimos [1].

O Rito Sumaríssimo é previsto no artigo 852-A e seguintes da Consolidação das Leis Trabalhistas (CLT), e versa normalmente sobre matérias não complexas. Para um processo se enquadrar neste rito é necessário que o valor da causa não exceda a 40 salários mínimos. Algumas características básicas desse tipo de processo é que os pedidos devem ser apresentados de forma líquida, os incidentes processuais devem ser necessariamente resolvidos em audiência e o número de testemunhas por parte deve ser duas.

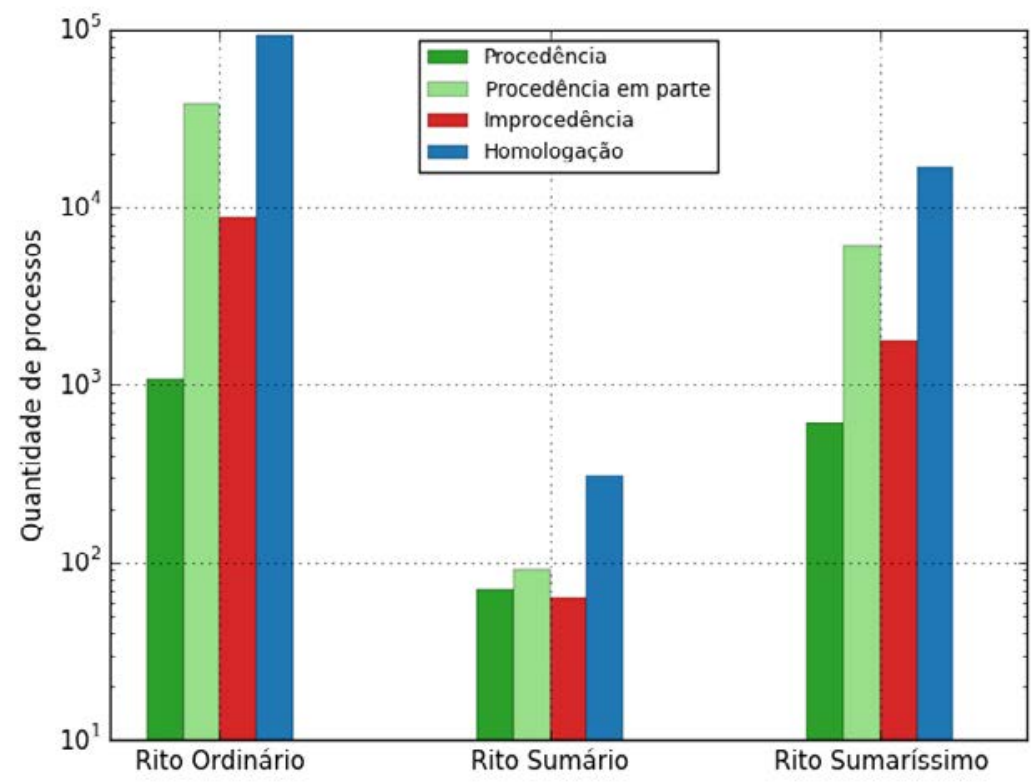

Figura 2. Quantidade de processos divididos por classes processuais. Para cada classe é mostrada a quantidade de processos procedentes (verde), procedentes em parte (verde claro), improcedentes (vermelho) ou processos com homologação de transação (azul).

No Rito Ordinário são enquadrados os processos que não se enquadram no Rito Sumário ou Sumaríssimo. Ele tem como características básicas: três testemunhas por parte (salvo o inquérito para apuração de falta grave que exige seis testemunhas), os pedidos podem ser ilíquidos e na sentença há exigência de relatório. É utilizado normalmente para causas mais complexas ou contra os entes públicos. 
Além das três classes processuais, iremos focar em quatro resultados que podem ocorrer nesses tipos de processo: procedência, procedência em parte, improcedente e homologação de transação. A procedência ocorre quando o juiz julga procedente o pedido, aceita o pedido do autor da ação e diz que ele tem razão, ou seja, o autor ganha a ação. A procedência em parte ocorre quando o juiz profere uma decisão dando ganho de causa parcial ao autor, ou seja, ele ganhou a ação, mas não o valor total solicitado. A improcedência ocorre quando o julgamento da causa é desfavorável ao autor, significa que o juiz deu ganho de causa para o réu e não para o autor, ou seja, o pedido do autor foi improcedente. Quando as duas partes entram em um acordo e o juiz homologa, estamos diante da homologação de transação. [11]

Por fim, iremos considerar apenas os processos que foram transitados em julgado, isso significa que chegaram ao fim. A decisão do juiz ou desembargador é definitiva e não pode mais ser modificada, portanto não é possível apresentar mais nenhum recurso. A figura 2 mostra todos os 166183 processos presentes na base de dados avaliada, o número de processos das diferentes classes e os diferentes resultados por classe. Repare que a classe Rito Sumário possui uma minoria dos processos (menos de 300) em qualquer resultado, enquanto o Rito Ordinário possui aproximadamente 10 mil processos (ou mais) em três resultados.

Os vértices da rede a ser construída a partir dos dados dos processos são advogados e uma aresta direcionada de um advogado $A$ para um $B$ indica que o advogado $A$ perdeu um processo para $B$. Portanto precisamos definir o significado de perder ou ganhar e para isso utilizaremos os resultados dos processos.

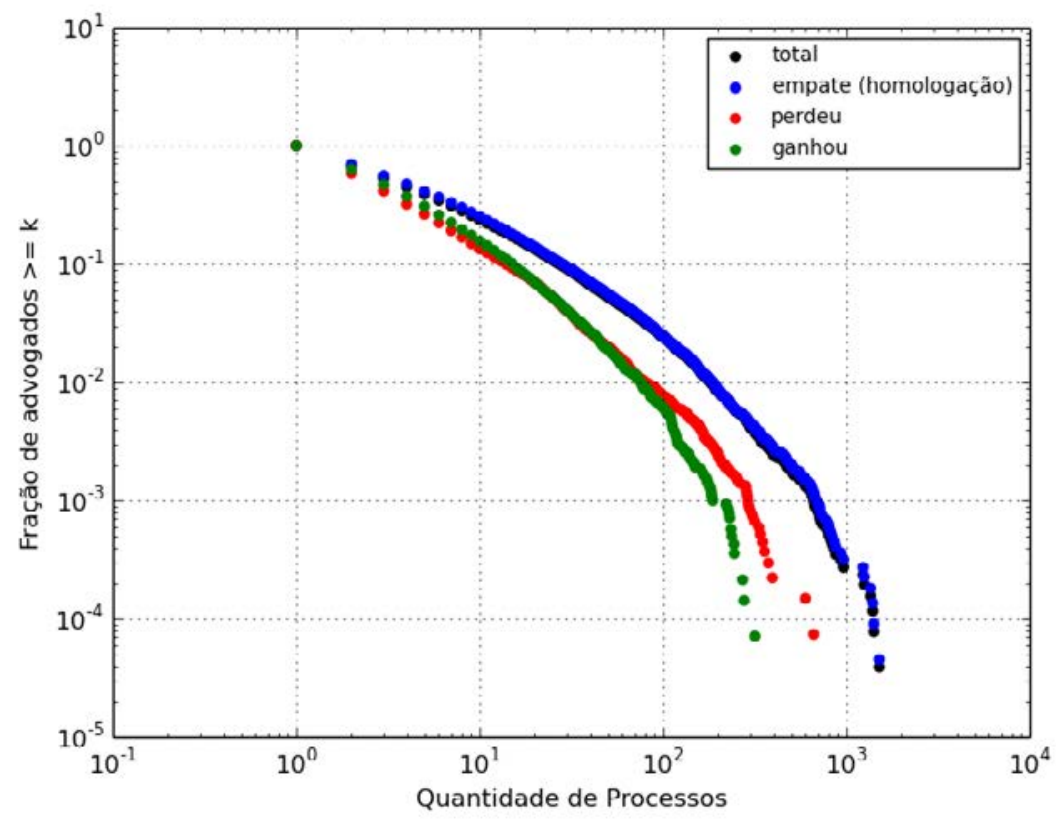

Figura 3. Distribuição Complementar Cumulativa Empírica (CCDF) de advogados que atuaram (preto), empataram (azul), ganharam (verde) ou perderam (vermeIho) em $k$ ou mais processos.

Nos processos que foram procedentes ou procedentes em parte consideramos que 
os advogados do autor (ou o advogado do autor, se existir apenas um) ganharam dos advogados do réu (ou do advogado do réu, se existir apenas um), dando origem a uma aresta direcionada de cada advogado do réu para cada advogado do autor. No caso de um processo improcedente consideramos o que os advogados do autor (ou o advogado do autor, se existir apenas um) perderam para os advogados do réu (ou do advogado do réu, se existir apenas um), dando origem a uma aresta direcionada do(s) advogado(s) do autor para o(s) advogado(s) do réu.

Nos casos de processos em que ocorreu a homologação de transação, as partes do processo chegaram a um acordo. Esses processos são a maioria, conforme ilustrado na figura 2, e esse comportamento é esperado pois a CLT torna obrigatória a proposta de conciliação, assim o acordo, na Justiça do Trabalho, tem prioridade absoluta [9]. Como houve um acordo no processo, não existiu um ganhador, por isso não iremos considerar processos homologados na rede pois eles não contribuem para a importância relativa dos advogados.

A figura 3 apresenta a fração de advogados da rede que atuaram em $k$ ou mais processos. É possível perceber que a maioria dos advogados da rede participaram de apenas um processo na justiça trabalhista, levando em conta a amostra de dados coletados para nossa rede. Pouco menos de $10 \%$ dos advogados ganharam ou perderam mais de 10 processos e este número cai para menos de $0.5 \%$ se tratando de 100 processos. Por outro lado, temos advogados que atuaram em mais de mil processos, indicando que a distribuição possui cauda pesada.

Outro ponto mostrado na figura é a grande quantidade de homologações entre advogados na rede, ou seja, ocorreu um acordo entre as partes e o juiz realizou uma homologação de transação. A cauda da distribuição de advogados que perderam processos é mais pesada do que a dos que ganharam, ou seja, é mais "fácil" (comum) perder do que ganhar. Além disso, a cauda da distribuição de advogados que homologaram processos é ainda mais pesada, ou seja, é mais "fácil" homologar um processo do que perdê-lo.

Tabela 1. Informações da rede

\begin{tabular}{|l|l|l|l|}
\hline Vértices & 17575 & Arestas & 113990 \\
\hline Diâmetro & 9 & Densidade & $3.69 \times 10^{-4}$ \\
\hline Grau médio (entrada + saída) & 12.97 & Distância média & 2.24 \\
\hline Grau mínimo de entrada & 0 & Grau mínimo de saída & 0 \\
\hline Grau máximo de entrada & 326 & Grau máximo de saída & 408 \\
\hline Componentes conexas & 177 & Tamanho da maior componente & $17173(97.71 \%)$ \\
\hline Componentes fortemente conexas & 9464 & $\begin{array}{l}\text { Tamanho da maior componente } \\
\text { fortemente conexa }\end{array}$ & $8080(45.97 \%)$ \\
\hline Coeficiente de clusterização local & $1.31 \times 10^{-2}$ & Coeficiente de clusterização global & $7.71 \times 10^{-3}$ \\
\hline Reciprocidade & 0.15 & & \\
\hline
\end{tabular}

\section{Análise da Rede}

A tabela 1 apresenta diversas informações sobre a estrutura da rede de advogados, que possui 17575 vértices (advogados) e 113990 arestas direcionadas. Nota-se ainda que a rede possui diversas características encontradas em outras redes reais [5]: 
- Distância e diâmetro baixos: A rede possui uma distância média muito pequena em relação a quantidade de vértices: a distância média entre 17575 vértices é de apenas 2.24. O diâmetro da rede também é bem pequeno em relação aos vértices: 9, ou seja, a maior distância entre dois vértices são 9 passos.

- Esparsa e conectada: Muitas redes reais são extremamente esparsas, exibindo uma densidade muito baixa (ordens de grandeza menor que 1), porém são extremamente "conectadas", com quase todos os vértices pertencendo à maior componente conexa. A rede de advogados possui uma densidade bem baixa $\left(3.69 \times 10^{-4}\right)$ e sua maior componente conexa possui $97.71 \%$ dos vértices da rede.

- Alto coeficiente de clusterização: Redes sociais estão cheias de triângulos, ou seja, se um advogado $A$ está relacionado aos advogados $B$ e $C$, é bem provável que os advogados $B$ e $C$ também estejam relacionados. O coeficiente de clusterização de muitas redes reais, que mede a tendência da rede a exibir triângulos, é ordens de magnitude maior que a densidade da rede. A rede de advogados possui o coeficiente de clusterização $\left(7.71 \times 10^{-3}\right)$ uma ordem de grandeza maior que a densidade da rede $\left(3.69 \times 10^{-4}\right)$. É importante notar que um único processo não gera nenhum triângulo na rede, pois um processo gera um grafo bipartido completo entre advogados das duas partes do processo.

- Distribuição de grau com cauda pesada: Em muitas redes reais, os graus dos vértices são bem desiguais, vértices com graus ordens de grandeza maior que a média são encontrados com probabilidade não desprezível, exibindo uma distribuição de grau com cauda pesada. A rede de advogados possui cauda pesada pois, como é possível ver na figura $4 \mathrm{a}$, podemos encontrar vértices com graus bem maiores que o grau médio da rede (12.97), com probabilidade não desprezível, tanto para o grau de entrada quanto para o grau de saída.

- Distribuição da força dos vértices: A força de um vértice é dada pela soma dos pesos de suas arestas de entrada ou saída, respectivamente. Na figura 4b, que mostra a distribuição das forças dos vértices, é possível ver que menos de $1 \%$ dos advogados trabalharam em centenas de processos. É interessante notar que a distribuição da força de entrada dos vértices possui a cauda menor que a distribuição da força de saída. Essa diferença é percebida para advogados que possuem mais de 100 processos, indicando ser mais fácil perder do que ganhar um processo.

A rede possui uma reciprocidade relativamente alta (0.15), significando que muitas vezes (15\%) os advogados, que se enfrentam, perdem um do outro mutuamente, em diferentes processos. Ou seja, não há uma preponderância significativa em sempre vencer (ou sempre perder) quando consideramos um par de advogados que se enfrentam.

\section{Ranqueamento de advogados}

A partir da estrutura da rede, queremos identificar os advogados mais influentes da justiça trabalhista do estado do Rio de Janeiro. Para isso utilizamos algumas métricas de centralidade para definir a importâncias relativa desses advogados.

A forma mais simples de medir a "importância" de um vértice em uma rede é considerar seu grau, ou seja, a quantidade de arestas de entrada no vértice, essa métrica é chamada de centralidade de grau. Porém, também é importante levar em conta o peso das arestas que apontam para o vértice, pois o peso de uma aresta direcionada, do vértice 

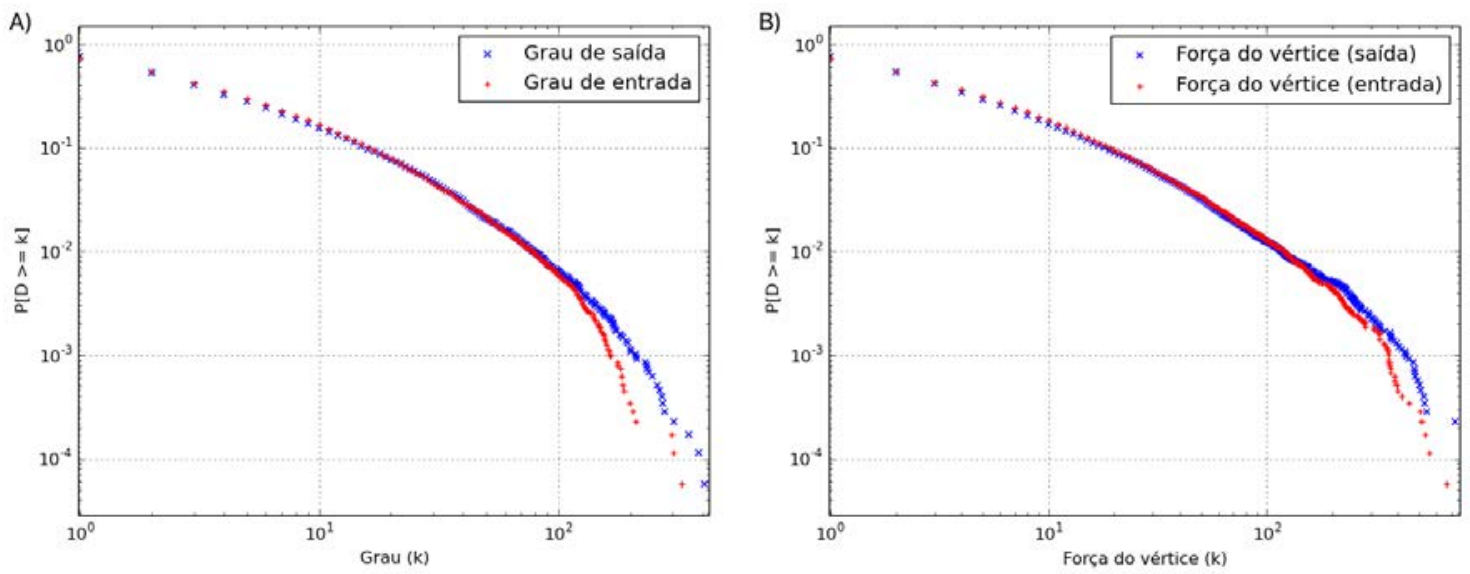

Figura 4. a) Distribuição Complementar Cumulativa Empírica (CCDF) dos graus de entrada e saída da rede. b) Distribuição Complementar Cumulativa Empírica (CCDF) das forças dos vértices (entrada e saída).

$A$ para o vértice $B$, é a quantidade de vezes que $B$ ganhou de $A$ e para isso utilizamos a força do vértice [2], que é dada por:

$$
S_{v}=\sum_{u \in \Gamma^{-}(v)} w_{u \rightarrow v}
$$

Onde $\Gamma^{-}(v)$ são todos os vértices vizinhos de $v$ que têm arestas apontando para $v$ e $w_{u \rightarrow v}$ é o peso da aresta direcionada de $u$ para $v$.

Na tabela 2 é possível ver os 10 vértices com maior força e seus respectivos graus, de entrada e saída. Repare que nem sempre o vértice com maior grau possui maior força, devido aos vértices que ganharam ou perderam várias vezes dos mesmos vértices, fazendo com que a aresta entre eles tenha um peso maior. É possível notar ainda os vértices com maior força de saída, ou seja, aqueles que mais perderam processos.

O pagerank [14], algoritmo desenvolvido pelos fundadores do Google, vem sendo utilizado para calcular a importância em redes direcionadas, levando em conta a qualidade e a quantidade de arestas que apontam para os vértices. $\mathrm{O}$ valor de pagerank de um vértice é definido recursivamente através da seguinte equação:

$$
P R(v)=\frac{(1-d)}{n}+d \sum_{u \in \Gamma^{-}(v)} \frac{P R(u) w_{u \rightarrow v}}{d^{+}(u)}
$$

Onde $d$ é o fator de amortecimento, que foi definido como 0.85 , valor tradicional utilizado em diversos artigos; $\frac{(1-d)}{n}$ é a importância mínima de um vértice na rede com $n$ vértices, que pode ser interpretado como sua aptidão externa; $\Gamma^{-}(v)$ são todos os vértices vizinhos de $v$ que têm arestas apontando para $v ; w_{u \rightarrow v}$ é o peso da aresta direcionada do vizinho $u$ de $v$ para $v$ e $d^{+}(u)$ é igual a soma dos pesos de todas as arestas direcionadas que saem de $u$. $\mathrm{O}$ valor de pagerank pode ser calculado através de um algoritmo iterativo até a convergência dos valores. 


\subsection{Ranqueamento dos vértices}

A tabela 3 apresenta os 10 primeiros advogados quando utilizamos diferentes métricas para realizar o ranqueamento. Como é possível notar, muitos advogados aparecem nas primeiras colocações no ranqueamento de mais de uma métrica. O advogado 16604 figura em primeiro na métrica de pagerank, isso mostra que ele têm grande importância no âmbito de processos trabalhistas. Ele também está em primeiro na métrica de betweenness, isso quer dizer que ele está no meio da rede e possui influência política. De fato, se trata de um advogado com mais de 20 anos de experiência que fundou seu escritório na década de 90. Processos vinculados a ele estão em vários tribunais do país, mostrando assim sua influência em nível nacional. Além do mais, recebeu em 2015 o título de cidadão honorário da cidade de São Paulo.

O advogado 13444 está entre os melhores nas métricas pagerank e betweenness. Ele também é um advogado importante na justiça trabalhista trabalhistas. 13444 é um advogado de renome com 36 anos de prática jurídica trabalhista na cidade do Rio de Janeiro.

Tabela 2. 10 maiores forças de advogados, tanto de entrada quanto de saída, e seus respectivos graus.

\begin{tabular}{|c|c|c|c|c|c|}
\hline \multicolumn{3}{|c|}{ Entrada } & \multicolumn{3}{c|}{ Saída } \\
\hline Advogado & $\begin{array}{c}\text { Grau do } \\
\text { vértice }\end{array}$ & $\begin{array}{c}\text { Força do } \\
\text { vértice }\end{array}$ & Advogado & $\begin{array}{c}\text { Grau do } \\
\text { vértice }\end{array}$ & $\begin{array}{c}\text { Força do } \\
\text { vértice }\end{array}$ \\
\hline 914 & 105 & 666 & 1772 & 408 & 1290 \\
\hline 4674 & 149 & 555 & 16604 & 351 & 928 \\
\hline 890 & 61 & 532 & 15928 & 84 & 908 \\
\hline 17522 & 117 & 512 & 9409 & 239 & 730 \\
\hline 14876 & 143 & 506 & 13155 & 247 & 541 \\
\hline 800 & 298 & 447 & 2471 & 192 & 529 \\
\hline 16496 & 149 & 417 & 9430 & 386 & 525 \\
\hline 17508 & 188 & 399 & 6942 & 235 & 508 \\
\hline 59 & 326 & 392 & 6538 & 234 & 502 \\
\hline 244 & 184 & 386 & 4048 & 116 & 492 \\
\hline
\end{tabular}

O advogado 9430 figura como o primeiro no ranqueamento de closeness e em sexto no ranqueamento de betweenness. Isso significa que esse advogado tende a conhecer muitos outros advogados, pois está próximo a outros advogados da rede, exercendo grande influência em seu círculo profissional. A revista Análise Advocacia 500 [4] traz os escritórios e advogados mais admirados no Brasil em cada ano. São vários critérios para definição dos advogados mais admirados, sendo o mais comum uma pesquisa de satisfação feita em grandes empresas ao redor do país. Na edição de 2014, encontramos o advogado 9430 entre os melhores advogados do estado do Rio de Janeiro. No entando, 9430 figura entre os 10 nos ranqueamentos de centralidade de grau e força de saída do vértice, sendo um dos advogados da rede com uma grande quantidade de processos perdidos.

O advogado 59 começou suas atividades em 1989 e está entre os 10 nos ranqueamentos de pagerank, betweenness e força do vértice. Também está em primeiro 
no ranking de centralidade de grau de entrada, ou seja, é o advogado que mais ganhou processos de advogados diferentes. É um advogado que atua em prol dos direitos dos trabalhadores nas cidades do Rio de Janeiro, Niterói e Nova Iguaçu, tendo atuado em um grande número de processos.

O advogado 15928, segundo no ranqueamento de pagerank, trabalha num dos maiores escritórios de advocacia do país. Esta empresa é reconhecida por analistas do mercado jurídico e por publicações realizadas na área, tendo ganhado inúmeros prêmios nos últimos anos, sendo um dos melhores escritórios de advocacia do Brasil em 12 áreas de atuação pela revista Análise Advocacia 5002015 [4], e um dos melhores escritórios de advocacia do Brasil em 22 áreas de atuação pela Chambers Latin America 2016 [3].

$\mathrm{O}$ advogado 9873 está presente nos ranqueamentos de pagerank, betweenness e closeness. Ele é co-autor de um livro na área de direito empresarial, trabalha em um grande escritório de advocacia do país e foi indicado um dos melhores advogados trabalhistas da américa latina em 2015 e 2016 pela LACCA no guia Latin Lawyer 250 [10].

Tabela 3. Top 10 advogados em cada métrica de centralidade.

\begin{tabular}{|c|c|c|c|c|}
\hline Pagerank & Força do vértice & Centralidade de grau & Closeness & Betweenness \\
\hline 16604 & 914 & 59 & 9430 & 16604 \\
\hline 15928 & 4674 & 943 & 1042 & 59 \\
\hline 59 & 890 & 800 & 7498 & 943 \\
\hline 6942 & 17522 & 3117 & 37 & 6942 \\
\hline 13155 & 14876 & 17134 & 4034 & 9873 \\
\hline 943 & 800 & 328 & 4662 & 9430 \\
\hline 13444 & 16496 & 1790 & 3570 & 13444 \\
\hline 17134 & 17508 & 17508 & 4853 & 13155 \\
\hline 9873 & 59 & 11278 & 4178 & 8284 \\
\hline 9409 & 244 & 244 & 7284 & 7927 \\
\hline
\end{tabular}

Quase a totalidade de advogados listados entre os 10 melhores em cada métrica possui anos de experiência na área de direito trabalhista. Esta observação indica que a rede de advogados construída pode de fato ser utilizada para identificar advogados influentes a partir de métricas de ranqueamento de vértices bem objetivas. Outro ponto interessante é que a boa parte dos advogados bem ranqueados atuam para funcionários e sindicatos. Muitos advogados acreditam que a legislação trabalhista no Brasil, muitas vezes considerada excessiva, favorece o trabalhador. Desta forma, ao dar uma proteção excessiva ao trabalhador, a Justiça acaba desprestigiando o trabalho e o emprego. Eles acreditam que esse cuidado concedido ao empregado é resultado de sua fraqueza em relação ao empregador. Outro ponto é que os altos índices de condenação das empresas são resultado da dificuldade que os empregadores têm em cumprir o excesso de normas que compõem a legislação trabalhista. [15]

A tabela 4 mostra a soma de todos os valores pedidos nos processos, divididos em homologados, procedentes e procedentes em parte e improcedentes, para cada advogado na métrica de força de entrada do vértice. É possível perceber que os maiores valores se encontram nos processos homologados. Os valores monetários possuem uma correlação com o ranqueamento, pois todos os 10 advogados melhores ranqueados possuem valores 
muito mais altos em seus processos procedentes do que em seus processos improcedentes. Os valores monetários dos processos não foram utilizados em nosso trabalho porque não representam quanto efetivamente foi ganho ou perdido em um processo, pois são valores pedidos no início do processo e não o valor real definido em sentença. A base de dados de onde foram coletados os dados não ofereceu este valor de forma fácil.

\section{Tabela 4. Top 10 advogados na métrica de força de entrada do vértice e a soma dos valores monetários pedidos nas causas que foram homologadas, proceden- tes e improcedentes.}

\begin{tabular}{|c|c|c|c|c|}
\hline & $\begin{array}{c}\text { Força de entrada } \\
\text { do vértice }\end{array}$ & $\begin{array}{c}\text { Homologação } \\
\text { por transação }\end{array}$ & $\begin{array}{c}\text { Procedentes e } \\
\text { Proc. em parte }\end{array}$ & Improcedentes \\
\hline 1 & 914 & $1.929 .663,78$ & $5.283 .287,24$ & $632.000,00$ \\
\hline 2 & 4674 & $2.354 .408,22$ & $4.835 .868,50$ & $682.748,05$ \\
\hline 3 & 890 & $1.999 .900,00$ & $8.165 .000,00$ & $1.227 .500,00$ \\
\hline 4 & 17522 & $8.027 .831,50$ & $8.381 .018,26$ & $2.757 .052,12$ \\
\hline 5 & 14876 & $2.284 .865,14$ & $4.426 .888,49$ & $622.748,05$ \\
\hline 6 & 800 & $11.719 .880,60$ & $10.175 .541,85$ & $1.277 .629,69$ \\
\hline 7 & 16496 & $5.700 .311,72$ & $2.101 .000,00$ & $724.534,80$ \\
\hline 8 & 17508 & $21.865 .543,78$ & $4.415 .000,00$ & $942.736,91$ \\
\hline 9 & 59 & $14.965 .705,43$ & $7.555 .000,00$ & $2.622 .000,00$ \\
\hline 10 & 244 & $21.123 .000,00$ & $4.175 .000,00$ & $832.736,91$ \\
\hline
\end{tabular}

\section{Conclusão}

Uma vez que muitas redes reais possam ser representadas a partir de dados coletados, utilizar métricas e técnicas que levem em conta a estrutura da rede para entender seu comportamento tem se tornado bem útil. Neste trabalho criamos uma rede de advogados trabalhistas do estado do Rio de Janeiro a partir de dados públicos sobre processos judiciais. Esta rede tem como objetivo capturar a importância relativa dos advogados, pois uma aresta direcionada de um advogado para outro é criada se o primeiro perdeu em um processo para o segundo. Uma avaliação empírica indicou que esta rede possui muitas características presentes em outras redes reais estudadas. A semelhança estrutural com essas redes permitiu utilizar as métricas apresentadas, como a força do vértice e o pagerank, para caracterizar o relacionamento entre os advogados.

Nossa abordagem para identificar os advogados mais influentes da rede identificou advogados com tradição na justiça do trabalho e com participação em muitos processos, inclusive com um deles sendo citado em uma revista especializada, como estando entre os melhores advogados do estado do Rio de Janeiro. Desta forma, ilustramos como a rede de advogados induzidos por processos judiciais trabalhistas pode ser utilizada para revelar aspectos importantes, como a importância relativa.

Como trabalhos futuros, propõe-se utilizar na representação da rede o valor ganho ou perdido em um processo e com isso utilizar outras métricas de centralidade para ranquear os advogados. 


\section{Referências}

[1] Patrícia Ribeiro de Azevedo e Kalina Valéria Bastos Pedroza. Procedimento Sumaríssimo: aspectos polêmicos. Acessado em 11/03/2016. URL: http : / / www . webartigos . com / artigos / procedimento-sumarissimotrabalhista-aspectos-polemicos/90877/.

[2] A. Barrat et al. "The architecture of complex weighted networks". Em: Proc. Natl. Acad. Sci. 101 (2004), pp. 3747-3752.

[3] Chambers e Partners. Chambers Latin America 2016. Acessado em 18/03/2016. URL: http : / / www . chambersandpartners . com / guide / latin america/9.

[4] Análise Editora. Advocacia 500 - 2014. Acessado em 16/12/2015. URL: http : / / www . analise.com/site/publicacoes / exibe/2/analiseadvocacia-500.

[5] Daniel Ratton Figueiredo. "Introdução a Redes Complexas". Em: Atualizações em Informática 2011. Ed. por Alberto Ferreira de Souza e Wagner Meira Jr. PUC-Rio, 2011. Cap. 7, pp. 303-358.

[6] James H. Fowler et al. Network Analysis and the Law: Measuring the Legal Importance of Precedents at the U.S. Supreme Court. 2007.

[7] Steven B. Andrews Herminia Ibarra. "Power, Social Influence, and Sense Making: Effects of Network Centrality and Proximity on Employee Perceptions". Em: Administrative Science Quarterly 38.2 (1993), pp. 277-303. ISSN: 00018392.

[8] Péterson Sampaio Procópio Júnior et al. "Time-aware Ranking in Sport Social Networks". Em: Journal of Information and Data Management (2012).

[9] Conselho Nacional de Justiça. Resolução $N^{o} 125$ de 29/11/2010. Acessado em 11/03/2016. URL: http : / / www . cnj . jus . br / busca-atos-adm? documento $=2579$.

[10] LACCA. Latin Lawyer 250. Acessado em 18/03/2016. URL: http : / / latinlawyer.com/11250/.

[11] Jocélia Lopes. Termos Judiciais. Acessado em 16/12/2015. URL: http : / / www . jocelialopesadvocacia.com.br/termos.html.

[12] M. E. J. Newman. "The structure of scientific collaboration networks". Em: Proceedings of the National Academy of Sciences 98.2 (2001), pp. 404-409.

[13] Mark E.J. Newman. "Complex Networks". Em: ed. por Eli Ben-Naim, Hans Frauenfelder e Zoltan Toroczkai. Berlin, Heidelberg: Springer Berlin Heidelberg, 2004. Cap. Who Is the Best Connected Scientist? A Study of Scientific Coauthorship Networks, pp. 337-370.

[14] Lawrence Page et al. The PageRank Citation Ranking: Bringing Order to the Web. Technical Report 1999-66. Previous number = SIDL-WP-1999-0120. Stanford InfoLab, nov. de 1999.

[15] Quem é protecionista é a legislação, não a Justiça do Trabalho, dizem advogados. http: / / www. conjur. com . br/2015-set-28/protetoratrabalhador-legislacao-nao-justica. Acessado em 16/12/2015.

[16] Filippo Radicchi. "Who Is the Best Player Ever? A Complex Network Analysis of the History of Professional Tennis". Em: PLoS ONE 6.2 (fev. de 2011), e17249. 